\title{
Estimation of the $\mathrm{F} 2$ generation segregation variance and relationships among growth, frost damage, and bud break in coastal Douglas-fir (Pseudotsuga menziesii (Mirb.) Franco) wide-crosses
}

\author{
Andy Benowicz ${ }^{1}$ - Michael Stoehr ${ }^{2}$ - Andreas Hamann ${ }^{3}$ - Alvin D. Yanchuk \\ Received: 9 July 2019 / Accepted: 21 January 2020 / Published online: 23 March 2020 \\ (C) Crown 2020
}

\begin{abstract}
- Key message Creation of second generation Douglas-fir (Pseudotsuga menziesii (Mirb.) Franco) hybrids based on parents from geographically distant locations did not appreciably increase variance in height, frost damage and bud break. New and favorable trait combinations between height and the two adaptive traits were found in the F2 populations.

- Context Increased genetic variance and new trait combinations can improve selection efficiency in terms of selection response and increased adaptability.

- Aims This project tested a novel method for generating higher genetic variance and new trait combinations in Douglas-fir populations.

- Methods Parents from Southern British Columbia (BC), Washington (WA), Oregon (OR), and Northern BC (NBC) were crossed within each provenance; then selections from BC were crossed with the other sources to create three F1 interpopulation generations. Unrelated random selections from the same F1 population were subsequently crossed to produce three F2 populations. The parental, F1 and F2 generations were concurrently grown in three field tests and were evaluated for height, frost damage, and bud break date.

- Results Significant segregation variances were found only in the BCxNBC cross for height in two sites and frost damage in one site and in the $\mathrm{BCxOR}$ cross for bud break in one site. In the $\mathrm{BCxNBC}$ cross, correlations between breeding values for height and frost damage changed from 0.71 in F1 to -0.04 in F2 and between height and bud break from -0.71 to -0.26 . In the BC-OR cross, correlations between height and bud break changed from -0.71 in F1 to -0.49 in F2.

- Conclusion Our results suggest that creation of wide-cross hybrids may not be very effective in increasing segregation variance in traditional tree improvement programs but in some cases may be considered to increase diversity of trait combinations.
\end{abstract}

Keywords Pseudotsuga menziesii · Genetic variance $\cdot$ Linkage $\cdot$ Intraspecific hybridization · Tree breeding

\section{Introduction}

Handling editor: Ricardo Alia

Contribution of the co-authors AB: writing - original draft, data analyses; MS: writing - review \& editing, data analyses, data curation, project administration; AH: writing - review \& editing, methodology, data collection, visualization; AYD: writing - review \& editing, data analyses.

Andy Benowicz andy.benowicz@gov.ab.ca

Authors affiliation extended at the last page of the article
Segregation variance refers to the increase in variance due to segregation of alleles in a second filial generation (F2) relative to variance observed in a first filial generation (F1) from different genetic lines or divergent populations. In divergent populations, quantitative traits values, even with the same mean, can be achieved by different combinations of alleles. When divergent populations are crossed, the variance of the $\mathrm{F} 1$ generation is not increased because all F1 offspring have heterozygous loci, with one allele from each divergent parent. 
However, an outbreak of variation due to recombination, the "segregation variance," can often be observed in the F2 generation (Wright 1968; Lande 1981). The magnitude of segregation variance depends on the extent of population differentiation and the genetic base for such differentiation including probability distributions of alleles and the number and effect size of alleles that contribute to a trait (Slatkin and Lande 1994; Koshy et al. 1998).

If genetic variation is due to numerous alleles with moderate to small effects, then the increase in segregation variance in the F2 generation is expected to be small. In contrast, a small number of large effect alleles and the potential occurrence of extreme phenotypes in the F2 generation will likely cause a substantial increase in segregation variance. Creation of interpopulation crosses based on divergent natural or breeding populations could, in theory, produce extreme phenotypes displaying values exceeding those observed in parental populations (Lynch and Walsh 1998). This effect, called transgressive segregation, can be due to epistasis, overdominance, and complementary action of additive genes. Complementary action of additive genes can be effective in increasing segregation variance if crosses are made between populations carrying various combinations of trait increasing and decreasing alleles (in contrast to where all increasing alleles are present in one population and all decreasing alleles in the other).

There are many examples of artificial selection for high and low trait values producing populations or lines sufficiently divergent to show segregation variance when the F2 crosses are produced (e.g., Sprague and Brimhall 1949; Mohamed and Hanna 1964; Busi et al. 2013). There are also examples of greater segregation variance in interspecies crosses based on natural populations (e.g., Val 1977; Fenster and Ritland 1994; Bradshaw et al. 1998; Nelson et al. 2003). However, we are not aware of any field studies reporting on the F2 generation segregation variance based on intraspecific crosses of divergent populations of trees. In a greenhouse study, Zhi (1999) evaluated F2 segregation variance in Douglas-fir (Pseudotsuga menziesii (Mirb.) Franco) wide-crosses based on 1-year-old seedlings. Examples of both, larger and smaller F2 variances compared to those of the F1 and parental populations were found depending on the trait, type of wide-cross, and the growing environment.

Genetic variation in Douglas-fir has been shown in numerous studies (e.g., Ferrell and Woodward 1966; Irgens-Moller 1967; Campbell and Sorensen 1978; LooDinkins et al. 1991; O'Neill et al. 2001; St. Clair et al. 2005; St. Clair 2006). It has been one of the most important commercial tree species in western North America, and as such it has also been subject to intensive tree breeding efforts over the last 60 years. The geographic distribution of the coastal variety (Pseudotsuga menziesii (Mirb.) Franco var. menziesii) spans approximately $2200 \mathrm{~km}$ in latitude (Hermann and Lavender 1990), and it is characterized by sharp longitudinal and gradual latitudinal environmental gradients. Using F1 crosses, Adams and Stoehr (2013) found evidence of transgressive segregation in several terpenes extracted from intraspecific Douglas-fir hybrids.

Lewontin and Birch (1966) suggested that interspecific crosses and intraspecies hybrids based on highly divergent populations can result in faster adaptations to new environments. In support of this statement, Rieseberg et al. (2003) showed that hybridization can be an important mechanism in adaptive evolution in wild sunflowers. Thus, formation of hybrid populations of commercial tree species may be of use to increase genetic variances for purposes of addressing adaptation in relation to climate change effects or forest health impacts. One might predict environmental conditions under one or more scenarios of climate warming and then carry out selections in adaptive traits so that they match these predicted environments (Hamann et al. 2001). Increased genetic variance in adaptive attributes in deployed populations can also be considered as a climate change mitigation management strategy for uncertain future environments.

In addition to potentially increasing variance in particular traits of interest, creation of F2 generations based on wide-crosses may change the strength of associations among traits and create new trait combinations. Creating genotypes with new trait combinations can also have value for climate change adaptation in forestry. For example, Heiner and Lavender (1972) showed that Oregon Douglas-fir seedlings from a southern, xeric location suffered less drought stress than seedlings from a northern, mesic location in an experiment controlling soil moisture availability. However, southern populations also set bud later and suffered greater frost damage in a common garden experiment (Campbell and Sorensen 1973). Planting stock that is resilient under climate change may therefore require a new combination of traits for drought tolerance and fall phenology timing that could potentially be created through selection of genotypes from F2 wide-crosses of northern and southern genotypes.

Assisted population migration is one of the methods of mitigating the impact of climate change on forests (e.g., Ledig and Kitzmiller 1992; Gray and Hamann 2011). It typically relies on testing a number of geographically 
diverse populations in common garden experiments to determine which populations will perform best in a target environment (e.g., Mátyás 1996). This approach can be most successful if populations best suited to the target site exist in another location within the species distribution range. However, it is likely that the populations best adapted to some specific local conditions will also show some degree of maladaptation to other, biotic or abiotic, conditions (Aitken and Whitlock 2013). Another way to increase the frequencies of favorable alleles in target environments is to deploy the intraspecific F2 crosses (between the local and nonlocal populations) in essentially new environments, thus potentially creating advantageous trait combinations looking for outliers as a useful source of material with improved adaptability.

In the present study, we evaluate a unique experiment with coastal Douglas-fir. Parents from southern coastal British Columbia provenances were crossed with the parents from provenances of Northern British Columbia, Washington, and Oregon to produce "wide-crosses." Randomly selected F1 individuals within each widecross were then crossed to create three F2 groups. In addition, within population (or provenance) crosses involving all selected parents were made to represent the parental generation. All three generations were grown in common garden experiments and were evaluated for growth, frost damage, and the timing of bud break. We investigate (1) whether crossing of geographically divergent Douglasfir populations results in the increased variance in the F2 generation and (2) how trait associations change from the F1 to the F2 generation. The results are discussed with respect to the utility of this approach in tree breeding as a method to enhance forest health and productivity in changing climates.

\section{Materials and methods}

\subsection{Crossing scheme}

This study was conceived and initiated by the late Gene Namkoong and co-workers. They took advantage of existing tests with progeny ranging in age from 19 to 30 years that were the result of "wide" crosses (F1) among geographically divergent parent trees as part of the British Columbia Douglas-fir breeding program (EP 519 (Orr-Ewing and Yeh 1978) and EP708 (Heaman 1982)). The original parents of these are growing in breeding arboreta and clonal archives at Cowichan Lake Research Station, while the F1 trees are growing in various tests on Vancouver Island, BC. All trees to be bred to produce seed to raise test seedlings for this

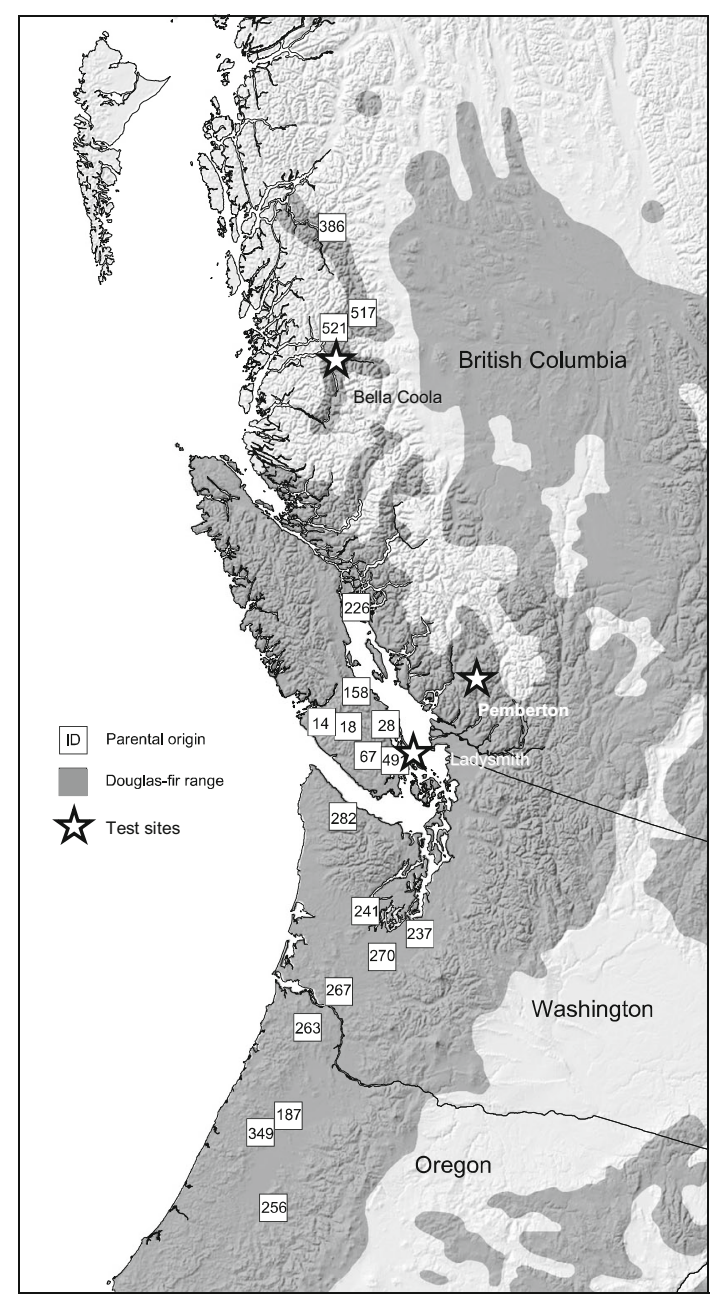

Fig. 1 Locations of parental selections and test sites

study (i.e., P0, F1, and F2) were partially girdled to stimulate male and female cones starting in 1990. Controlled pollinations were carried out at the breeding arboreta and clonal archives to generate the P0 and F1 seeds and at F1 progeny trials to generate F2 seed over the next 2 years for this experiment.

Specifically, Douglas-fir trees from Southern British Columbia (BC), Washington (WA), Oregon (OR), and Northern British Columbia (NBC) (Fig. 1) were crossed within each region according to the crossing scheme in Table 1 to create four parental populations: BC-P0, NBC-P0, WA-P0, and OR-P0. In addition, parents from $\mathrm{BC}$ were crossed with selections from the other three regions to create three wide-cross hybrid offspring (F1) populations (BCxNBC-F1, BCxWA-F1, and BCxOR-F1) giving rise to three, five and four full-sib families per wide-cross, respectively (Table 1).

Next, three F2 populations were generated (BCxNBCF2, BCxWA-F2, and BCxOR-F2) so that each F2 family 
Table 1 Mating design for the within parental source crossing (P0, cross ID's in italic font) and the between source wide-crossing (F1, normal font)

\begin{tabular}{|c|c|c|c|c|c|c|c|c|c|c|c|c|c|c|c|c|c|c|}
\hline \multirow[b]{2}{*}{ Parent } & & \multicolumn{6}{|c|}{$\mathrm{BC}$} & \multicolumn{5}{|l|}{ WA } & \multicolumn{4}{|l|}{ OR } & \multicolumn{2}{|c|}{$\mathrm{NBC}$} \\
\hline & & 18 & 28 & 67 & 158 & 226 & 491 & 237 & 241 & 267 & 270 & 282 & 187 & 256 & 263 & 349 & 386 & 521 \\
\hline $\mathrm{BC}$ & 14 & 1 & 2 & 3 & & & & & & & & & 4 & & & & & \\
\hline $\mathrm{BC}$ & 28 & 5 & & & 6 & 7 & & & & & & & & 8 & & & & 9 \\
\hline $\mathrm{BC}$ & 67 & 10 & 11 & & 12 & & 14 & & & & & & & & 13 & & & \\
\hline $\mathrm{BC}$ & 226 & & & & & & & & & 16 & & & & & & & & \\
\hline $\mathrm{BC}$ & 383 & & 33 & 34 & 35 & & & & & & & 36 & & & & & & \\
\hline $\mathrm{BC}$ & 491 & & & & & & & & & & & & & & & & 37 & \\
\hline $\mathrm{BC}$ & 492 & & & 38 & & & & & & & & & & & & & & \\
\hline WA & 237 & & & & 17 & & & & 18 & & 19 & & & & & & & \\
\hline WA & 241 & & 20 & & & & & & & 21 & & & & & & & & \\
\hline WA & 270 & & & 25 & & & & & 26 & & & 27 & & & & & & \\
\hline WA & 282 & & & & & & & 28 & 29 & & & & & & & & & \\
\hline OR & 187 & & & & & & & & & & & & & 15 & & & & \\
\hline OR & 263 & & & & & & & & & & & & 22 & 23 & & 24 & & \\
\hline OR & 349 & 30 & & & & & & & & & & & 31 & 32 & & & & \\
\hline NBC & 517 & & & 40 & & & & & & & & & & & & & 41 & 42 \\
\hline
\end{tabular}

Numbers indicate parental or cross ID

had four different grandparents to avoid effects of inbreeding (Table 2). Seeds from all 56 families from the 10 cross types (four parental populations, three F1, and three F2 hybrid cross types) were sown in early 1996 to produce seedlings for field test planting. It should be noted that the NBC parents might have come from the Douglas-fir interior variety $[P$. menziesii var. glauca (Beissn.) Franco] or were hybrids of the two varieties. The distribution range of the interior variety comes close to the coast in the northern part of the species distribution range (Farrar 1995).

Table 2 Mating design for the generation of F2 crosses

\begin{tabular}{|c|c|c|c|c|c|c|c|c|c|c|c|}
\hline \multirow[b]{2}{*}{ Parent } & & \multicolumn{3}{|c|}{$\mathrm{BCxOR}$} & \multicolumn{5}{|c|}{ BCxWA } & \multicolumn{2}{|c|}{$\mathrm{BCxNBC}$} \\
\hline & & 4 & 13 & 30 & 16 & 17 & 20 & 25 & 36 & 9 & 37 \\
\hline $\mathrm{BCxOR}$ & 4 & & 101 & & & & & & & & \\
\hline $\mathrm{BCxOR}$ & 8 & 104 & 102 & 105 & & & & & & & \\
\hline BCxOR & 13 & & & 103 & & & & & & & \\
\hline $\mathrm{BCxOR}$ & 30 & 106 & & & & & & & & & \\
\hline BCxWA & 17 & & & & & & 111 & & 110 & & \\
\hline BCxWA & 20 & & & & 113 & & & & 112 & & \\
\hline BCxWA & 25 & & & & & 107 & 109 & & & & \\
\hline BCxWA & 36 & & & & & & & 108 & & & \\
\hline $\mathrm{BCxNBC}$ & 40 & & & & & & & & & 114 & 115 \\
\hline
\end{tabular}

Numbers indicate parental and cross ID's. Parental ID's correspond to the cross ID's from Table 2

\subsection{Field study}

Containerized seedlings from all 56 families were planted in March 1997 in 3 environmentally contrasting locations: Ladysmith, BC (latitude $49^{\circ} 00^{\prime} \mathrm{N}$, longitude $123^{\circ} 51^{\prime} \mathrm{W}$, elevation $107 \mathrm{~m}$ ); Pemberton, $\mathrm{BC}$ (latitude $50^{\circ} 35^{\prime} \mathrm{N}$, longitude $123^{\circ} 18^{\prime} \mathrm{W}$, elevation $400 \mathrm{~m}$ ); and Bella Coola, BC (latitude $52^{\circ} 29^{\prime} \mathrm{N}$, longitude $126^{\circ} 33^{\prime} \mathrm{W}$, elevation $285 \mathrm{~m}$ ). Ladysmith is characterized by warm, dry summers, and moist mild winters with little snowfall $\left(8.3^{\circ} \mathrm{C}\right.$ mean annual temperature, $210 \mathrm{~mm}$ growing season precipitation, and $130 \mathrm{~mm}$ precipitation as snow). Pemberton is located in a transitional zone between the coast and interior and is characterized by warm summers and moist, cool winters with moderate snowfall $\left(6.1^{\circ} \mathrm{C}\right.$ mean annual temperature, $350 \mathrm{~mm}$ growing season precipitation, and $530 \mathrm{~mm}$ precipitation as snow). The northern coastal Bella Coola site is characterized by moist summers and mild winters with moderate snowfall $\left(6.5^{\circ} \mathrm{C}\right.$ mean annual temperature, $530 \mathrm{~mm}$ growing season precipitation, and $380 \mathrm{~mm}$ precipitation as snow).

Excluding border trees, a total of 1002, 955, and 1016 seedlings were planted in Ladysmith, Pemberton, and Bella Coola, respectively. On average each family was represented by 18 seedlings per site. A randomized block design was used with three blocks per site and six seedlings per family per block randomly allocated within each block. The following attributes were measured: height at ages 1, 2, 3, 4, and 11 (denoted as Ht1, Ht2, etc.), fall frost damage at age 4, and the timing of bud break at age 5. Ht11 was not measured in Bella Coola due to difficult access. 
To determine the onset of fall frost hardiness, laboratory freezing tests were conducted on all trees at two test temperatures. Three $10-\mathrm{cm}$ long shoot tips from secondorder branches in the upper crown were collected between October 15 and 24, stored on ice, and subjected to artificial freeze tests within 24 (higher temperature) and $48 \mathrm{~h}$ (lower temperature). The samples were subjected to a 12$\mathrm{h}$ cooling period from $+2{ }^{\circ} \mathrm{C}$ to $-6{ }^{\circ} \mathrm{C}$, a 4 -h ramp-down phase to the freezing target ranging from $-16^{\circ} \mathrm{C}$ to $-22{ }^{\circ} \mathrm{C}$ which was held for $2 \mathrm{~h}$, and finally a 4-h rampup phase to $2{ }^{\circ} \mathrm{C}$. The two freezing temperature targets were determined by prior tests for samples from each plantation so that approximately 30 and $70 \%$ freeze damage were achieved. Freeze damage was visually scored for percent discoloration after 5 days of storage at room temperature in the dark. Scoring ranged from " 0 " for no damage to " 10 " for $100 \%$ needle necrosis. To evaluate timing of bud break measurements of leader extension were carried out four times starting in the beginning of May in approximately weekly intervals. The date when buds elongated beyond the bud scales by a minimum of $1 \mathrm{~cm}$ was determined for each tree and used as a bud break date expressed as day of year.

\subsection{Statistical methods}

General linear mixed models were solved with ASReml (Gilmour et al. 2009). As some parents were used as female and male, an overlay design matrix model was applied (Gilmour et al. 2009). First-order two-dimensional (row and column) autoregressive correlation structure was used to model spatial residual variances in the test sites. Data from each site were analyzed separately and then together with the data from the other sites. Since none of the investigated traits showed statistically significant segregation variance based on the combined data set, only segregation variance results from the individual sites are presented. The objective of this analysis was to evaluate variance changes from generation to generation for the crosses related to the selected few parents from each of the four base populations. Consequently, as different subsets of $\mathrm{BC}$ parents were used to create crosses with parents from the other populations, three $\mathrm{BC} 0$ variances were estimated based on the crosses between the $\mathrm{BC}$ parents used in a particular F1 crossing. Each of the three wide-crosses was analyzed separately. The following model was used to evaluate segregation variance:

$Y_{\mathrm{ijk} l}=\mu+R_{\mathrm{j}}+S_{k}+\mathrm{P}(\mathrm{S})_{\mathrm{kl}}+\mathrm{e}_{\mathrm{ijkl}}$

where $Y_{\mathrm{ijk} 1}$ is an $\mathrm{i}^{\text {th }}$ individual from the $\mathrm{kl}^{\text {th }}$ parent in the $\mathrm{j}^{\text {th }}$ block, $\mu$ is an overall mean, $R_{j}$ is the fixed effect of the $j^{\text {th }}$ block, and $S_{k}$ is the fixed effect of the $\mathrm{k}^{\text {th }}$ source generation: (BC-P0, WA-P0, BCxWA-F1, BCxWA-F2) or (BC-P0, OR-
P0, BCxOR-F1, BCxOR-F2) or (BC-P0, NBC-P0, BCxNBC$\mathrm{F} 1, \mathrm{BCxNBC}-\mathrm{F} 2) . \mathrm{P}(\mathrm{S})_{\mathrm{kl}}$ is the random effect of $1^{\text {th }}$ parent within source $\sim \operatorname{Diagonal}\left(\operatorname{IID}\left(0, \sigma_{\mathrm{kl}}^{2}\right)\right.$ ) and allows a different parental variance for each source generation; $\mathrm{e}_{\mathrm{ijkl}}$ is the residual divided into: (1) the spatially independent random residual $\sim \operatorname{Diagonal}\left(\operatorname{IID}\left(0, \sigma_{\mathrm{ke}}^{2}\right)\right.$ ) allows a different residual variance for each source generation and (2) spatially dependent residual.

Segregation variance $\sigma_{\mathrm{s}}{ }^{2}$ was calculated using the following two methods (Lande 1981):

$\sigma^{2}{ }_{S}=\sigma_{F 2}^{2}-\sigma_{F 1}^{2}$

$\sigma_{\mathrm{S}}^{2}=\sigma_{\mathrm{F} 2}^{2}-\left(0.5 \sigma_{\mathrm{F} 1}^{2}+0.25 \sigma_{\mathrm{P} 01}^{2}+0.25 \sigma_{\mathrm{P} 02}^{2}\right)$

where $\sigma_{\mathrm{F} 1}^{2}, \sigma_{\mathrm{F} 2}^{2}, \sigma_{\mathrm{P} 01}^{2}$, and $\sigma_{\mathrm{P} 02}^{2}$ are residual variances in the $\mathrm{F} 1, \mathrm{~F} 2$, and the parental populations within each wide cross as explained above $\left(\sigma_{\mathrm{ke}}^{2}\right)$.

Since both methods of segregation variance calculation produced similar values of $\sigma_{s}^{2}$, only results for the second method are shown. The advantage of the second method is that if there is a relationship between the population residual variance and heterozygosity, then this method of segregation variance calculation partially accounts for this effect (Wright 1968). The significance of differences in residual variance $\left(\sigma_{\mathrm{ke}}^{2}\right)$ between generations was evaluated with the REML likelihood ratio test (Gilmour et al. 2009). The LogL values of the model with two residual variances were subtracted from the $\log \mathrm{L}$ values of the reduced model (i.e., one with the combined residual variance). The significance was determined by comparing $2 \times \Delta \log L$ values with the critical value of the chisquare distribution value at one $\mathrm{df}$ and $\alpha=0.05$.

The relationship between the traits by wide cross was evaluated using individual tree breeding values (BV). Best linear unbiased predictions (BLUP) were calculated for all parents and progeny using a pedigree-based additive numerator relationship matrix (for details see section 9 of Gilmour et al. 2009). The following model was used:

$Y_{\mathrm{ijk}}=\mu+T_{\mathrm{k}}+\mathrm{R}(\mathrm{L})_{\mathrm{jk}}+A_{\mathrm{ijk}}+T A_{\mathrm{ijk}}+e_{\mathrm{ijk}}$

where $Y_{\mathrm{ijk}}$ is an $\mathrm{i}^{\text {th }}$ individual from the $\mathrm{k}^{\text {th }}$ test site in the $\mathrm{j}^{\text {th }}$ block, $\mu$ is an overall mean, $T_{k}$ is the fixed effect of the $k^{\text {th }}$ test site, $R(L)_{j k}$ is the fixed effect of the $\mathrm{j}^{\text {th }}$ block within the $\mathrm{k}^{\text {th }}$ test site, $A_{\text {iik }}$ is the random effect of the $\mathrm{ijk}^{\text {th }}$ genotype $\sim \operatorname{IID}(0$, $\left.\left.\sigma^{2}{ }_{\mathrm{A}}\right)\right), \mathrm{TA}_{\mathrm{ijk}}$ is the random interaction of test site with genotype $\sim \operatorname{IID}\left(0, \sigma_{\mathrm{TA}}^{2}\right)$ ), and $\mathrm{e}_{\mathrm{ijk}}$ is the random residual $\sim \operatorname{IID}\left(0, \sigma_{\mathrm{E}}^{2}\right)$ ).

Data from all 56 crosses from the 3 test sites were included in the BV analysis. This approach is different from the one used for the evaluation of segregation variance which was specific to each wide cross and each test site (examples of significant segregation variance were found only for individual sites). As 
some $\mathrm{BC}$ parents were used in more than 1 wide cross, incorporation of pedigree information from all 56 crosses results in more reliable BV's than those calculated based on data subsets for each wide cross. Using data from all three sites increases sample size per parent and allows for the inclusion of genotype by environment interaction in the model.

Pearson product-moment correlations between the BV's for growth, frost damage and bud break were calculated by generation for each of the three wide crosses. Height at age 4 was selected to explore the relationship between growth and the two adaptive attributes. It was selected to maximize the sample size as it allowed for inclusion of the Bella Coola data (age 11 was not measured in this site). The relationship between growth and adaptive attributes is likely to hold at older age as a strong correlation was found between BV's for Ht4 and Ht11 $(r=0.89)$ based on the Ladysmith and Pemberton data (not shown).

\section{Results}

\subsection{Height}

The test sites differed to some extent in productivity. At age 4, the mean height in Bella Coola, Ladysmith, and Pemberton was 135,167 , and $127 \mathrm{~cm}$, respectively. Fourth-year survival was high in all sites ranging from 97 to $98 \%$ and was also good at age 11 (i.e., 91\% in Ladysmith and 94\% in Pemberton). At age 11, the Ladysmith site was still somewhat more productive than the Pemberton site (mean height 665 vs. $573 \mathrm{~cm}$ ). The height of the BC-P0 population was lower than the height of the WA-P0 population, greater than the height of the NBC-P0 population and approximately of the same size as the OR-P0 population (Table 3).

Significant segregation variance in height was found in the $\mathrm{BCxNBC}$ cross, while there was no evidence of greater F2 height variance in the $\mathrm{BCxOR}-\mathrm{F} 2$ and the $\mathrm{BCxWA}-\mathrm{F} 2$ cross type. Significant segregation variance in the BCxNBC-F2 crosses was found at several ages in Ladysmith and Pemberton (Table 3) but not at the Bella Coola site (results not shown). In Pemberton, the segregation variance increased markedly from ages 1 to 4 and remained high at age 11 (Fig. 2a). In Ladysmith, the F2 segregation variance was the greatest at age 2 and then decreased gradually up at age 11 (Fig. 2b). The segregation variance was statistically significant at ages 3, 4, and 11 in Pemberton and at ages 1, 2, and 3 in Ladysmith (Table 3).

\subsection{Frost damage}

At the time of sampling, trees in Ladysmith and Pemberton had similar average frost damage (6.6 in both sites) and were more frost hardy than those in Bella Coola (7.5). The NBC and WA parental populations were significantly more frost hardy than the $\mathrm{BC}$ parental population, while no difference was found between BC-P0 and OR-P0. The difference between $\mathrm{BC}-\mathrm{P} 0$ and NBC-P0 was much greater than the difference between $\mathrm{BC}-\mathrm{P} 0$ and WA-P0. The results for Pemberton are presented in Table 4.

Significant segregation variance in frost damage was found in the BCxNBC cross in Pemberton (Table 4) but not in Ladysmith and Bella Coola (results not shown). There was no evidence of greater F2 variance in frost damage in the BC-WA and BC-OR crosses in any of the three test sites.

\subsection{Timing of bud break}

Growth started first in Ladysmith (test mean 134.3) followed by Pemberton (139.2) and Bella Coola (144.3). OR parental population broke bud significantly earlier (by 5 days) than the $\mathrm{BC}$ parental population in Ladysmith (Table 4) but not in the other two sites. There was no difference in the timing of bud break between the NBC-P0 and BC-P0 in any site. BC-P0 broke bud earlier than WA-P0 in Ladysmith (by 3 days) and in Pemberton (by 1 day) but not in Bella Coola.

A significant segregation variance in bud break was found in the BCxOR cross in Ladysmith (Table 4) but not in the other two sites. There was no significant segregation variance in bud break in the $\mathrm{BCxNBC}$ and the BCxWA crosses in any site (results not shown).

\subsection{Correlations between traits by generation}

Based on progeny breeding values, the correlations within the P0 generations between growth and frost damage and between growth and the timing of bud break were not strong in all four populations. The strongest correlation was found for the NBC-P0 between $\mathrm{Ht} 4$ and frost damage at $r=0.52$ (Fig. 3a1).

In the $\mathrm{F} 1$ generations, strong correlation across sites was found in the $\mathrm{BCxNBC}$ cross between growth and frost damage and between growth and bud break and in the $\mathrm{BCxOR}$ cross between growth and bud break. In the BCxNBC-F1 crosses, taller trees were significantly less frost hardy than smaller ones $(r=0.71)$ (Fig. 3a1) and had a tendency to break buds earlier $(r=-0.71)$ (Fig. 3b1). Similarly, in the BCxOR F1 generation, taller trees broke bud earlier than the smaller ones $(r=-0.71)$ (Fig. 3c1). The correlations in the BCxWA F1 generation were weaker at $r=0.22$ between height and frost damage and $r=-$ 0.45 between height and bud break (not shown). In the F2 generations, there was no correlation between height and frost damage in the BCxNBC cross $(r=-0.04)$ (Fig. 3a2). The mean population frost damage was the same in BCxNBC-F1 and $\mathrm{BCxNBC}-\mathrm{F} 2$. Compared to the correlations in the F1 generation, weaker correlations between height and bud break were 
Table 3 Mean height, measured at Ladysmith and Pemberton test sites, with standard deviations (SD), residual variance within populations $\left(\sigma^{2}\right.$ ke), and F2 segregation variance (F2 seg. var.), where applicable

\begin{tabular}{|c|c|c|c|c|c|c|c|c|c|c|c|}
\hline \multicolumn{7}{|c|}{ Ladysmith } & \multicolumn{5}{|c|}{ Pemberton } \\
\hline Trait & Pop. & $\mathrm{N}$ & Mean $(\mathrm{cm})$ & $\mathrm{SD}(\mathrm{cm})$ & $\sigma_{\mathrm{ke}}^{2}$ & F2 seg. var. (\%) & $\mathrm{N}$ & Mean $(\mathrm{cm})$ & $\mathrm{SD}(\mathrm{cm})$ & $\sigma_{\mathrm{ke}}^{2}$ & F2 seg. var. (\%) \\
\hline Ht11 & BC-P0 & 117 & $661.6 \mathrm{a}$ & 101.0 & 5180.2 & & 115 & $553.6 \mathrm{a}$ & 100.7 & 4641.2 & \\
\hline Ht11 & WA-P0 & 98 & $701.9 b$ & 89.6 & 4430.0 & & 80 & $620.2 b$ & 115.2 & 6170.3 & \\
\hline Ht11 & BCxWA-F1 & 60 & 675.1 & 97.2 & 3747.4 & & 49 & 568.8 & 136.4 & $10,715.2$ & \\
\hline Ht11 & BCxWA-F2 & 112 & 647.6 & 101.8 & 5922.3 & 38 & 101 & 567.4 & 118.0 & 9911.7 & 23 \\
\hline Ht11 & BC-P0 & 79 & $694.2 \mathrm{a}$ & 115.6 & 7075.2 & & 75 & $592.8 \mathrm{a}$ & 103.1 & 4943.1 & \\
\hline Ht11 & OR-P0 & 95 & $699.2 \mathrm{a}$ & 101.1 & 5119.0 & & 94 & $573.1 \mathrm{a}$ & 91.0 & 3052.1 & \\
\hline Ht11 & BCxOR-F1 & 63 & 705.4 & 113.9 & 5091.8 & & 68 & 601.6 & 94.4 & 5026.9 & \\
\hline Ht11 & BCxOR-F2 & 95 & 682.3 & 100.5 & 4822.6 & -14 & 99 & 580.8 & 94.1 & 4298.9 & -5 \\
\hline Ht11 & BC-P0 & 30 & $649.7 \mathrm{a}$ & 106.9 & 6377.6 & & 31 & $583.0 \mathrm{a}$ & 94.3 & 2990.5 & \\
\hline Ht11 & NBC-P0 & 30 & $562.0 \mathrm{~b}$ & 80.1 & 2277.6 & & 29 & $515.9 \mathrm{~b}$ & 68.2 & 1338.9 & \\
\hline Ht11 & BCxNBC-F1 & 47 & 621.0 & 127.2 & 8340.4 & & 31 & 538.0 & 89.2 & 4313.8 & \\
\hline Ht11 & BCxNBC-F2 & 47 & 583.9 & 115.6 & 8510.0 & 34 & 51 & 564.4 & 107.6 & 7752.1 & $139 *$ \\
\hline Ht4 & BC-P0 & 30 & $159.8 \mathrm{a}$ & 31.0 & 606.5 & & 31 & $126.0 \mathrm{a}$ & 23.7 & 186.5 & \\
\hline $\mathrm{Ht} 4$ & NBC-P0 & 30 & $137.6 \mathrm{a}$ & 24.1 & 193.0 & & 29 & $112.8 \mathrm{a}$ & 20.6 & 223.5 & \\
\hline $\mathrm{Ht} 4$ & BCxNBC-F1 & 47 & 150.7 & 32.9 & 595.3 & & 31 & 113.7 & 23.5 & 362.2 & \\
\hline $\mathrm{Ht} 4$ & BCxNBC-F2 & 47 & 151.9 & 39.0 & 821.4 & 65 & 51 & 122.0 & 31.9 & 618.9 & $118^{*}$ \\
\hline $\mathrm{Ht} 3$ & BC-P0 & 30 & $121.6 \mathrm{a}$ & 21.3 & 329.9 & & 31 & $83.3 \mathrm{a}$ & 15.7 & 117.5 & \\
\hline $\mathrm{Ht} 3$ & NBC-P0 & 30 & $110.5 \mathrm{a}$ & 17.7 & 95.5 & & 29 & $75.0 \mathrm{a}$ & 14.8 & 138.7 & \\
\hline Ht3 & BCxNBC-F1 & 47 & 113.9 & 24.6 & 381.6 & & 31 & 74.7 & 16.2 & 184.7 & \\
\hline Ht3 & BCxNBC-F2 & 47 & 117.9 & 31.4 & 567.6 & $91^{*}$ & 51 & 81.3 & 21.1 & 305.3 & $95^{*}$ \\
\hline Ht2 & BC-P0 & 30 & $91.2 \mathrm{a}$ & 15.2 & 182.6 & & 31 & $57.6 \mathrm{a}$ & 8.7 & 53.5 & \\
\hline Ht2 & NBC-P0 & 30 & $83.8 \mathrm{a}$ & 13.3 & 84.0 & & 29 & $51.7 \mathrm{a}$ & 8.1 & 51.1 & \\
\hline Ht2 & BCxNBC-F1 & 47 & 83.6 & 17.9 & 216.0 & & 31 & 50.3 & 9.9 & 80.0 & \\
\hline $\mathrm{Ht} 2$ & BCxNBC-F2 & 47 & 87.2 & 24.1 & 393.7 & $125^{*}$ & 51 & 55.5 & 10.6 & 85.1 & 29 \\
\hline Ht1 & BC-P0 & 30 & $48.7 \mathrm{a}$ & 5.8 & 22.4 & & 31 & $42.8 \mathrm{a}$ & 5.1 & 26.9 & \\
\hline Ht1 & NBC-P0 & 30 & $44.6 \mathrm{a}$ & 5.2 & 23.0 & & 29 & $39.2 \mathrm{a}$ & 6.3 & 34.6 & \\
\hline Ht1 & BCxNBC-F1 & 47 & 45.2 & 8.5 & 63.2 & & 31 & 37.0 & 6.9 & 51.7 & \\
\hline Ht1 & BCxNBC-F2 & 47 & 49.0 & 10.3 & 94.3 & $120 *$ & 51 & 41.3 & 6.1 & 34.8 & -15 \\
\hline
\end{tabular}

For each population, all age 11 results are included; for other ages, only populations with at least one significant increase in $\mathrm{F} 2$ segregation variance are shown. Significantly greater F2 variances $(p \leq 0.05)$ are marked with *. Parental population means followed by different letters indicate significant differences between the means $(p \leq 0.05)$

found in the $\mathrm{F} 2$ generation for the $\mathrm{BCxNBC}$ and $\mathrm{BC}-\mathrm{OR}$ crosses at $r$ values of -0.26 and -0.49 , respectively (Fig. 3 $\mathrm{B} 2$ and $\mathrm{C} 2$ ). In the BCxWA cross, the F2 generation correlations were only slightly lower than those in the F1 generation with $r$ values of 0.13 and -0.39 between height and frost damage and height and bud break, respectively (not shown).

\section{Discussion}

Instances of significant segregation variance resulting from crossing F1 populations from geographically distant parental sources of Douglas-fir were found in all three examined traits: height growth, frost damage, and bud break. However, segregation variance in height and frost damage was only found in the $\mathrm{BCxNBC}$ cross and in bud break only in the $\mathrm{BC}-\mathrm{OR}$ cross. In addition, the results were site-dependent: significant increases in the $\mathrm{F} 2$ variance in height at several ages were found in Ladysmith and Pemberton, while significant segregation variance in frost damage and bud break was only found in Pemberton and Ladysmith, respectively.

The apparent lack of segregation variance in most cross/ trait combinations may have resulted from small genetic differentiation between the sampled groups of parents and/or from the additive polygenic mode of inheritance. Wright (1968) formulated the relationship between the magnitude of difference between two inbred lines, the number of genes causing this difference, and their segregation variance. Lande (1981) showed that this relationship can be extended to genetically heterogeneous populations. There are several 

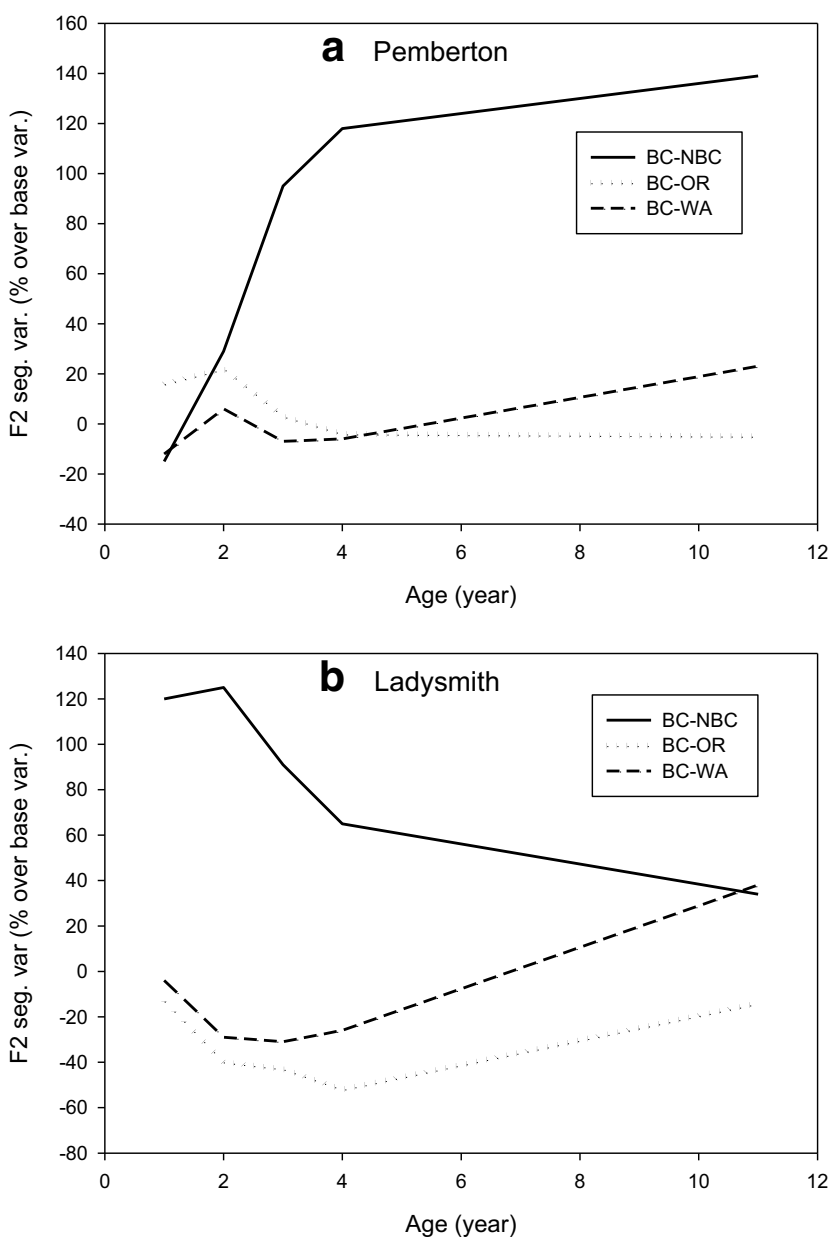

Fig. 2 Relative magnitude of segregation variance from ages 1 to 11 for $\mathrm{BCxNBC}, \mathrm{BCxOR}$, and BCxWA height. $\mathrm{a}=$ Pemberton, $\mathrm{b}=$ Ladysmith

Table 4 Timing of bud break in Ladysmith and frost damage in Pemberton, with standard deviations (SD), residual variance within modifications of the Wright's equation, but the basic form is as follows:

$\mathrm{n}_{\mathrm{e}}=\left(\mu_{2}-\mu_{1}\right)^{2} / 8 \sigma_{\mathrm{s}}^{2}$

where $\mathrm{n}_{\mathrm{e}}$ is the minimum number of segregating loci (assumed unlinked with only additive alleles of the same effect size), $\mu_{1}$ and $\mu_{2}$ are parental population means, and $\sigma_{\mathrm{s}}{ }^{2}$ is the segregation variance. Without differences in gene frequencies, there is no segregation variance, and differences due to a large number of genes will result in a small segregation variance. It is noteworthy that Wright's method can be significantly impacted by dominance, linkage, unequal allelic effects, and opposing allelic effects present in each parental population (Wright 1968; Zeng et al. 1990; Zeng 1992; Otto and Jones 2000). In coastal Douglas-fir, significant additive and nonadditive effects were shown with respect to height growth (Yanchuk 1996).

Small genetic differences between the populations or polygenic nature of larger differences can result in nonsignificant segregation variance due to the insufficient sample size and the obscuring effects of environment. In this study, the impact of within-site heterogeneous environmental conditions on genetic variance estimations was reduced by replications and the spatial modeling of residual variance. Despite this, for some traits, differences between the F2 and F1 variance as large as $65 \%$ were not statistically significant.

Differences in environmental conditions between the sites and between different assessment ages also likely affected segregation variance estimates. For example, OR parental population broke buds significantly earlier than the BC parental population in Ladysmith but not in Pemberton and Bella populations $\left(\sigma_{\mathrm{ke}}^{2}\right)$, and F2 segregation variance (F2 seg. var.), where applicable

\begin{tabular}{|c|c|c|c|c|c|c|c|c|c|c|}
\hline \multirow[b]{2}{*}{ Pop. } & \multicolumn{5}{|c|}{ Bud break Ladysmith (day of year) } & \multicolumn{5}{|c|}{ Frost damage Pemberton (score 0 to 10 ) } \\
\hline & $N$ & Mean & SD & $\sigma_{\mathrm{ke}}^{2}$ & F2 seg. var. $(\%)$ & $N$ & Mean & SD & $\sigma_{\mathrm{ke}}^{2}$ & F2 seg. var. $(\%)$ \\
\hline BC-P0 & 35 & $137 \mathrm{a}$ & 4.6 & 19.3 & & 33 & $8.3 \mathrm{a}$ & 2.2 & 3.2 & \\
\hline NBC-P0 & 34 & $136 \mathrm{a}$ & 4.8 & 19.1 & & 28 & $2.5 \mathrm{~b}$ & 3.0 & 7.9 & \\
\hline BCxNBC-F1 & 49 & 133 & 5.0 & 17.2 & & 31 & 3.5 & 2.9 & 6.8 & \\
\hline $\mathrm{BCxNBC-F2}$ & 50 & 136 & 4.4 & 17.4 & -4 & 50 & 4.9 & 3.7 & 11.7 & $89^{*}$ \\
\hline BC-P0 & 89 & $136 \mathrm{a}$ & 5.1 & 19.9 & & 76 & $8.5 \mathrm{a}$ & 2.2 & 3.4 & \\
\hline OR-P0 & 106 & $131 b$ & 4.6 & 9.2 & & 94 & $7.5 \mathrm{a}$ & 3.2 & 7.0 & \\
\hline BCxOR-F1 & 70 & 132 & 5.3 & 10.8 & & 59 & 7.5 & 3.2 & 9.8 & \\
\hline BCxOR-F2 & 107 & 132 & 4.8 & 18.7 & $47 *$ & 98 & 7.2 & 3.1 & 7.2 & -4 \\
\hline BC-P0 & 122 & $134 a$ & 5.0 & 13.5 & & 108 & $7.3 \mathrm{a}$ & 3.1 & 7.5 & \\
\hline WA-P0 & 111 & $137 b$ & 4.4 & 8.5 & & 87 & $5.3 b$ & 3.6 & 11.6 & \\
\hline BCxWA-F1 & 65 & 133 & 5.6 & 9.3 & & 49 & 5.5 & 3.8 & 13.0 & \\
\hline BCxWA-F2 & 120 & 137 & 4.3 & 12.2 & 20 & 108 & 7.3 & 3.1 & 7.1 & -37 \\
\hline
\end{tabular}

Significantly greater F2 variances $(\mathrm{p} \leq 0.05)$ are marked with *. Parental population means followed by different letters indicate significant differences between the means $(\mathrm{p} \leq 0.05)$ 

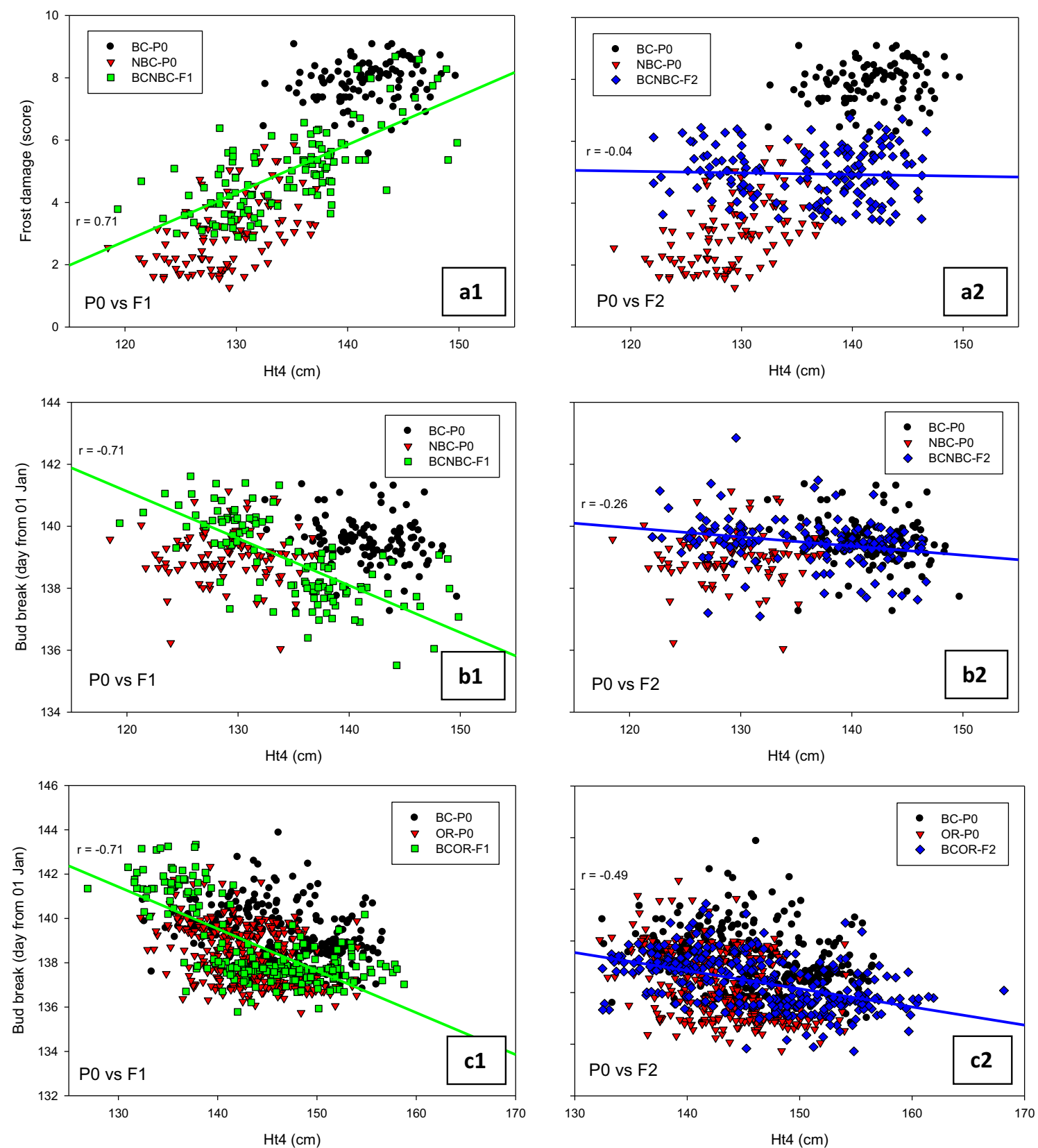

Fig. 3 Parental, F1 and F2 generation individual tree breeding values. $\mathrm{BCxNBC}$ frost damage and height at age four (a1, a2); BCxNBC bud break and height at age 4 (b1, b2); BCxOR bud break and height at age 4 (c1, c2). Frost damage was scored from 0 (no damage) to 10 (complete

Coola. Correspondingly, significant segregation variance in bud break was found only in Ladysmith. Even if the magnitude of divergence between the parental populations remains similar in different sites, genotype by environment interaction may still be a reason why the segregation variance was often different in different environmental conditions. For example, the difference in frost damage between the $\mathrm{NBC}$ and the $\mathrm{BC}$ parental populations was the same in Ladysmith and Pemberton, yet only in Pemberton there was a significant increase in segregation variance. Environmental conditions damage). Regression lines are based on the progeny data only (F1 green, F2 blue). All correlations are significant at $p<0.001$ except for the correlation in $\mathrm{A} 2(p=0.604)$

differed substantially between the Ladysmith (milder, drier site) and Pemberton (colder, moister site) sites. It is possible that the range of frost damage values was not fully expressed in Ladysmith if the trees on this site were not subject to the same frost hardiness triggering conditions as those in the colder Pemberton site.

The observed fluctuations with age in the height segregation variance could have resulted from differential sensitivity to the changing environmental conditions. In Pemberton, the coldest site, the increase in segregation variance with age in 
the $\mathrm{BCxNBC}$ cross could have resulted from the accumulated effects of tissue damage due to low temperatures. In Ladysmith, the site prone to drought, segregation variance in the $\mathrm{BCxNBC}$ cross was the greatest at the young age and then gradually decreased. Since drought and frost resistance can be correlated in Douglas-fir (e.g., White 1987; Bansal et al. 2015), it is reasonable to expect drought-induced differences in growth in the $\mathrm{BCxNBC}$ cross type in moisture limiting conditions such as those present in Ladysmith. Trees are most susceptible to drought after planting and, once established, suffer less from low moisture. Thus, a relatively greater range of height values is expected at a younger age for moisturelimited growth.

A possible example of transgressive segregation was found in the BCxOR cross. Some F2 generation individuals had $\mathrm{Ht} 4$ BVs exceeding the parental BV range at the high end (Fig. $3 \mathrm{c} 2$ ). There was little evidence of differences in growth rates between both parental populations. The lack of differences in growth rate could have resulted from negative correlations between the traits affecting growth. Examples of such negative correlations were found in two hardwood species whose northern populations had shorter growing season but greater rates of photosynthesis per unit leaf area compared to the southern sources when evaluated in common garden experiments (Benowicz et al. 2000). If the OR source achieved the same growth as the BC source due to different combinations of growth increasing and decreasing alleles, then it is possible that segregation produced the extreme height individuals found in the F2 generation.

The sample size needed to find extreme genotypes is strongly influenced by the genetic architecture that causes the difference between the populations. The number of different genotypes created in the F2 generation depends on three factors: the number of different loci affecting the trait, the number of alleles per locus, and the degree of linkage (Acquaah 2012). For example, if the parents differ in four loci each with two alleles per locus, and there is no linkage, then the minimum sample size for a chance to include all genotypes in the test is 256 (Acquaah 2012). However, very large sample sizes lead to increases in environmental variance and are often impractical in forestry. The number of genetic factors affecting a trait is almost always unknown, but there may be indications from literature that variations in a trait of interests are based on a smaller number of genes. It is noteworthy that the number of genes affecting segregation variance refers to the genes causing differences between the populations (i.e., gene frequencies) and not the total number of genes affecting a trait. The mode of inheritance can be polygenic, but the difference between particular populations may still be due to a small number of genes.

Despite the potential difficulties and uncertainties associated with estimation of segregation variance in large forestry experiments, this study shows that transient increases in the
F2 variance can be present when crossing divergent natural populations. Among the evaluated wide crosses, the $\mathrm{BCxNBC}$ cross produced the strongest evidence of increased F2 variance. The reason for this may be a larger difference between the parental populations and/or a presence of a gene or genes of larger effects. The NBC parents were from the area close to the northern distribution limit of coastal Douglas-fir with perhaps steeper environmental gradients than those present between the BC and OR or WA. As explained before, it is possible that these parents were actually from the Douglas-fir interior variety or were hybrids of the two varieties.

Evaluations of geographically distant populations revealed trade-offs between growth and fall frost hardiness in several conifers including interior Douglas-fir (Rehfeldt 1979; Howe et al. 2003). In this study, the NBC-P0 trees were significantly smaller and more frost hardy than the BC-P0 trees. However, within populations the relationship between growth and frost hardiness is often weaker and variable (Aitken and Hannerz 2001). Aitken et al. (1996) studied two coastal Douglas-fir populations and found a high genetic correlation between needle cold injury and growth in one breeding zone $(r=0.72)$ but not in the other $(r=0.11)$. Hawkins and Stoehr (2009) looked at F1 crosses of coastal Douglas-fir from southern BC and northern Washington and found genetic correlation between height growth and fall frost injury based on individual trees $(r=0.52)$. Similarly, in this study, individuals from the hybrid BCxNBC-F1 population showed a strong positive correlation between height growth and frost damage $(r=0.71)$. However, in the F2 generation, there was no correlation between height and injury due to the exposure to low temperatures. While change in pleiotropic effects could be the reason, it is more likely that the transient nature of the height frost injury correlation observed in this study was due to change in genetic linkage. Howe et al. (2003) hypothesized that linkage disequilibrium may be the cause of correlation between growth and frost hardiness.

If forward selections were made from the $\mathrm{BCxNBC}$ wide cross, then selection efficiency in the F2 generation would increase considerably due to the generational change in the correlation between growth and frost damage (rather than due to segregation variance). Selection of, for example, the top $20 \%$ trees for growth would result in gain of 5.8\% and 6.2\% for the F1 and F2 generations, respectively. However, it would also result in an increase in frost damage of $30 \%$ in the F1 selections compared to a reduction of $-3 \%$ in the $\mathrm{F} 2$ selections.

A positive correlation between bud break and growth was found in the $\mathrm{BCxNBC}$ and the $\mathrm{BCxOR}$ wide-crosses. Individuals that broke buds earlier had a tendency to have higher growth rate. Again, in the F2 generation the relationship between bud break and growth was weaker, particularly in the $\mathrm{BC}-\mathrm{NBC}$ cross. This change in the correlation strength is advantageous for the simultaneous selection for greater growth rate and lower spring frost damage. In both wide-

\section{פs springer INRAC}


crosses, there were a number of $\mathrm{F} 2$ trees with the more favorable combination of growth rate and timing of bud break than those found in the F1 individuals.

It is likely not a coincidence that the high F1 correlation between traits was found only in trait/wide-cross combinations for which significant segregation variance was found. As noted before, segregation variance can appear in the F2 generation if there are differences in allele frequencies between the parental populations. Also linkage disequilibrium is created when crossing populations that have different allele frequencies (Slatkin 2008). In all three cases of high F1 correlations, one or both of the traits showed examples of increased segregation variance: height and frost damage in the $\mathrm{BCxNBC}$ cross and bud break in the $\mathrm{BCxOR}$ cross. Thus, high correlations found for these specific trait/wide-cross combinations in the F1 hybrid generation strengthen the evidence that the increase in the $\mathrm{F} 2$ generation within-family variance was caused by segregation.

Under certain conditions, creation of wide-cross hybrid populations may be tried mainly as a method to create new, favorable trait combinations. Deployment of nonlocal sources, a practice often used in forestry, results in the introduction of all traits from the source population, some of which may be unfavorable in target environments at later dates. The expression of maladapted alleles in common garden experiments lowers the risk of deploying unsuitable seed sources but, at the same time, makes it often impossible to identify the potentially favorable traits present in these seed sources. We have shown that a different approach to utilize nonlocal genetic material is to consider deploying hybrids based on the local and distant parents. For example, in the BCxNBC cross, the F2 generation produced many individuals with high growth rate and low frost damage, a combination of traits not seen in either parental population or in the F1 trees. In the $\mathrm{BCxOR}$ cross, a number of fast-growing $\mathrm{F} 2$ trees broke buds later than the F1 fast-growing trees and thus would be more suitable for planting on sites prone to late spring frost. This method may be efficient and effective for species with short generation time, when a large number of plants per cross is planted and clonal testing is employed to better separate environmental and genetic effects.

\section{Conclusion}

This project tested a novel method for generating higher genetic variance and new trait combinations in populations to improve selection efficiency in terms of selection response and increased adaptability. The F1 and F2 progeny from a wide cross study were evaluated in common garden experiments for growth, timing of bud break, and frost damage. Significant segregation variance was observed in all three traits but only in certain crosses and in particular environments. The variance differences were typically small, however, likely due to small divergence among the intraspecific parental populations, the nature of polygenic inheritance affecting the traits, and the effects of environmental conditions across different sites. The strength of correlations between frost damage, bud break, and growth found in some hybrid crosses decreased considerably after one cycle of breeding, likely due to a breakdown in linkage disequilibrium. Our results indicate that creation of hybrid populations based on wide crosses may not appreciably increase variance of a particular trait but under certain conditions can still be tried to increase diversity of trait combinations. Given highly unpredictable impact of climate change on forest ecosystems and the ecological and commercial importance of trees, it is warranted to diversify methods aimed at advancing forest growth and health.

Acknowledgments The concept and the design of this experiment were the works of Dr. G. Namkoong and Dr. M. Koshy at the University of British Columbia.

Funding information Financial support was provided by the British Columbia Ministry of Forests, Lands, Natural Resource Operations and Rural Development. Partial support to A. Benowicz was provided by the Alberta Agriculture and Forestry.

Data availability The datasets generated during the current study belong to the British Columbia Ministry of Forests, Lands, Natural Resource Operations and Rural Development. They are available from Michael Stoehr on reasonable request.

\section{Compliance with ethical standards}

Conflict of interest The authors declare that they have no conflict of interest.

\section{References}

Acquaah G (2012) Principles of plant genetics and breeding. WileyBlackwell, Chichester

Adams RP, Stoehr MU (2013) Multivariate detection of hybridization using conifer terpenes II: analysis of terpene inheritance patterns in Pseudotsuga menziesii F1 hybrids. Phytologia 95(1):42-57

Aitken SN, Hannerz M (2001) Genecology and gene resource management strategies for conifer cold hardiness. In: Bigras FJ, Columbo SJ (eds) Conifer cold hardiness. Kluwer Academic Publishers, Dordrecht, pp 23-53

Aitken SN, Whitlock MC (2013) Assisted gene flow to facilitate local adaptation to climate change. Annu Rev Ecol Syst 44:367-388. https://doi.org/10.1146/annurev-ecolsys-110512-135747

Aitken SN, Adams WT, Shermann N, Fuchigami LH (1996) Family variation for fall cold hardiness in two Washington populations of Douglas-fir (Pseudotsuga menziesii var. menziesii (Mirb.) Franco). For Ecol Manag 111:119-126. https://doi.org/10.1016/03781127(95)03609-1

Bansal S, Harrington CA, Gould PJ, St Clair JB (2015) Climate-related genetic variation in drought resistance of Douglas-fir (Pseudotsuga 
menziesii). Glob Chang Biol 21:947-958. https://doi.org/10.1111/ gcb. 12719

Benowicz A, Guy RD, El-Kassaby YA (2000) Geographic pattern of genetic variation in photosynthetic capacity and growth in two hardwood species from British Columbia. Oecologia 123:168-174. https://doi.org/10.1007/s004420051002

Bradshaw HD Jr, Otto KG, Frewen BE, McKay JK, Schemske DW (1998) Quantitative trait loci affecting differences in floral morphology between two species of monkeyflower (Mimulus). Genetics 149:367-382

Busi R, Neve P, Powles S (2013) Evolved polygenic herbicide resistance in Lolium rigidum by low-dose herbicide selection within standing genetic variation. Evol Appl 6(2):231-242. https://doi.org/10.1111/ j.1752-4571.2012.00282.x

Campbell RK, Sorensen FC (1973) Cold-acclimation in seedling Douglasfir related to phenology and provenance. Ecology 54:1148-1151

Campbell RK, Sorensen FC (1978) Effect of test environment on expression of clines and on delimitation of seed zones in Douglas-fir. Theor Appl Genet 51:233-246. https://doi.org/10.1007/ BF00273770

Farrar JL (1995) Trees in Canada. Fitzhenry \& Whiteside Ltd and the Canadian Forest Service, Markham

Fenster CB, Ritland K (1994) Quantitative genetics of mating system divergence in the yellow monkeyflower species complex. Heredity 73:422-435. https://doi.org/10.1038/hdy.1994.190

Ferrell WK, Woodward EW (1966) Effects of seed origin on drought resistance of Douglas-fir (Pseudotsuga menziesii) (Mirb) Franco. Ecology 47:499-503. https://doi.org/10.2307/1932994

Gilmour AR, Gogel BJ, Cullis BR, Thompson R (2009) ASReml user. Guide release 3.0. VSN International Ltd., Hemel

Gray LK, Hamann A (2011) Strategies for reforestation under uncertain future climates: guidelines for Alberta, Canada. PLoS One 6: e22977. https://doi.org/10.1371/journal.pone.0022977

Hamann A, Koshy M, Namkoong G (2001) A multiple population breeding strategy for uncertain climatic futures: a case study with red alder. In: Mueller-Starck G, Schubert R (eds) Genetic response of forest systems to changing environmental conditions. Kluwer Academic Publishers, Dordrecht, pp 321-330

Hawkins BJ, Stoehr M (2009) Growth, phenology, and cold hardiness of 32 Douglas-fir full-sib families. Can J For Res 39:1821-1834. https://doi.org/10.1139/X09-092

Heaman JC (1982) A breeding program in coastal Douglas-fir (P. menziesii Mirb. (Franco)) 1979-1981. In pollard DFW, Edwards DG, Yeatman CW (eds). Proc. of $18^{\text {th }}$ Canadian tree Improv. Assoc. meeting, Duncan, BC

Heiner TD, Lavender DP (1972) Early growth and drought avoidance in Douglas-fir seedlings. In: Forest research laboratory research paper no. 14. Oregon State University, Corvallis

Hermann RK, Lavender DP (1990) Pseudotsuga menziesii (Mirb.) Franco. In: Burns RM, Honkala BH (eds) Silvics of North America, Conifers. Agriculture handbook 654, vol 1. U.S. Department of Agriculture, Forest Service, Washington DC, pp 527-540

Howe GT, Aitken SN, Neale DB, Jermstad KD, Wheeler NC, Chen THH (2003) From genotype to phenotype: unraveling the complexities of cold adaptation in forest trees. Can J Bot 81(12):1247-1266. https:// doi.org/10.1139/b03-141

Irgens-Moller H (1967) Patterns of height growth initiation and cessation in Douglas-fir. Silvae Genet 16:56-58

Koshy MP, Namkoong G, Roberds JH (1998) Genetic variance in the F2 generation of divergently selected parents. Theor Appl Genet 97: 990-993

Lande R (1981) The minimum number of genes contributing to quantitative variation between and within populations. Genetics 99:541-553

Ledig FT, Kitzmiller JH (1992) Genetic strategies for reforestation in the face of global climate change. For Ecol Manag 50:153-169

Lewontin RC, Birch LC (1966) Hybridization as a source of variation for adaptation to new environments. Evolution 1966:315-336
Loo-Dinkins JA, Ying CC, Hamm EA (1991) Stem volume and wood relative density of a non-local Douglas-fir provenance in British Columbia. Silvae Genet 40:29-35

Lynch M, Walsh B (1998) Genetics and analysis of quantitative traits. Sinauer Associates, Sunderland

Mátyás C (1996) Climatic adaptation of trees: rediscovering provenance tests. Euphytica 92:45-54

Mohamed AH, Hanna AS (1964) Inheritance of quantitative characters in rice. Estimation of the number of effective pairs controlling plant height. Genetics 49:81-93

Nelson CD, Weng C, Kubisiak TL, Stine M, Brown CL (2003) On the number of genes controlling the grass stage in longleaf pine. J Hered 94(5):392-398. https://doi.org/10.1093/jhered/esg086

O’Neill GA, Aitken SN, Adams WT (2001) Genetic selection for cold hardiness in coastal Douglas-fir seedlings and saplings. Can J For Res 30:1799-1807. https://doi.org/10.1139/cjfr-30-11-1799

Orr-Ewing AL, Yeh FCH (1978) Survival and growth traits of racial crosses with Douglas-fir. Research notes no. 85. Ministry of Forests, Province of British Columbia, Victoria

Otto SP, Jones CD (2000) Detecting the undetected: estimating the total number of loci underlying a quantitative trait. Genetics 156:2093-2107

Rehfeldt GE (1979) Ecological adaptations in Douglas-fir (Pseudotsuga menziesii var.glauca) populations. I. North Idaho and north-East Washington. Heredity 43:383-397

Rieseberg LH, Raymond O, Rosenthal DM, Lai Z, Livingstone K, Nakazato T, Durphy JL, Schwarzbach AE, Donovan LA, Lexer C (2003) Major ecological transitions in annual sunflowers facilitated by hybridization. Science 301:1211-1216. https://doi.org/10.1126/ science. 1086949

Slatkin M (2008) Linkage disequilibrium - understanding the evolutionary past and mapping the medical future. Nat Rev Genet 9:477-485. https://doi.org/10.1038/nrg2361

Slatkin M, Lande R (1994) Segregation variance after hybridization of isolated populations. Genet Res 64:51-56. https://doi.org/10.1017/ S0016672300032547

Sprague GF, Brimhall B (1949) Quantitative inheritance of oil in the corn kernel. Agron J 41:30-33

St. Clair JB (2006) Genetic variation in fall cold hardiness in coastal Douglas-fir in western Oregon and Washington. Can J Bot 84 1110-1181. https://doi.org/10.1139/B06-084

St. Clair JB, Mandel NL, Vance-Borland KW (2005) Genecology of Douglas-fir in western Oregon and Washington. Ann Bot 96: 1199-1214. https://doi.org/10.1139/B06-084

Val FC (1977) Genetic analysis of the morphological differences between two interfertile species of Hawaiian Drosophila. Evolution 31:611629. https://doi.org/10.2307/2407526

White TL (1987) Drought tolerance of southwestern Oregon Douglas-fir. For Sci 33:283-293

Wright S (1968) Evolution and the genetics of populations, vol 1: genetic and biometric foundations. The University of Chicago Press, Chicago

Yanchuk AD (1996) General and specific combining ability from disconnected partial diallels of coastal Douglas-fir. Silvae Genet 45(1):37-45

Zeng Z-B (1992) Correcting the bias of Wright's estimates of the number of genes affecting a quantitative character: a further improved method. Genetics 131:987-1001

Zeng Z-B, Houle D, Cockerham CC (1990) How informative is Wright's estimator of the number of genes affecting a quantitative character? Genetics 126:235-247

Zhi J (1999) Theoretical models of segregation variance in the F2 populations and their application in Douglas-fir. Master of Science Thesis, University of British Columbia

Publisher's note Springer Nature remains neutral with regard to jurisdictional claims in published maps and institutional affiliations. 


\section{Affiliations}

\section{Andy Benowicz ${ }^{1} \cdot$ Michael Stoehr $^{2} \cdot$ Andreas Hamann $^{3} \cdot$ Alvin D. Yanchuk ${ }^{2}$}

1 Alberta Agriculture and Forestry, Edmonton, AB T5K 2M4, Canada

2 Forest Improvement and Research Management Branch, BC

Ministry of Forests, Lands, Natural Resource Operations and Rural Development, Saanichton, BC V8M 1W4, Canada
Department of Renewable Resources, Faculty of Agricultural, Life, and Environmental Sciences, University of Alberta,

Edmonton, AB T6G 2H1, Canada 